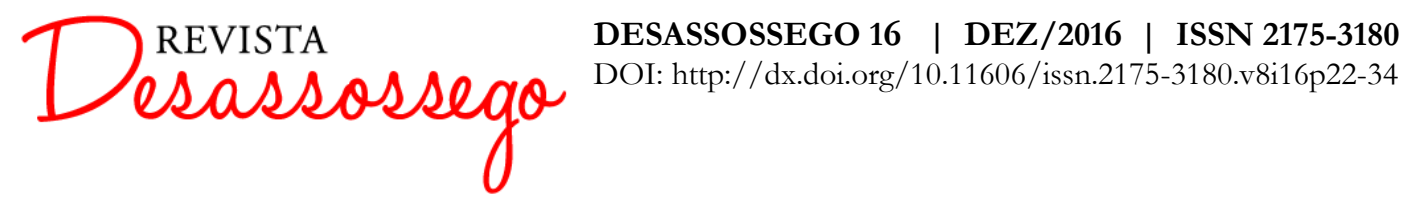

\title{
A PERSONAGEM PLANA E A REPRESENTAÇÃO DO MEDO COMO ESTEIOS DE A INSTALAÇÃO DO MEDO, DE RUI ZINK
}

\author{
Mauro Dunder ${ }^{1}$
}

\begin{abstract}
Resumo: A partir das reflexões teóricas de Michel Zéraffa (2010) e Carlos Reis (2014), nos campos da teoria do romance e da narratologia, respectivamente, este artigo realizará uma análise do processo constitutivo de $A$ instalação do medo (2012), do romancista português Rui Zink, a partir do pressuposto de que a obra lança mão da construção de personagens planas, na acepção de E. M. Forster, para constituir não apenas a realidade em que elas se inserem, mas para, a partir dela, estabelecer uma possibilidade de leitura da realidade em que se insere o leitor, caracterizando o fenômeno da metalepse, como a compreende a teoria dos estudos narrativos.
\end{abstract}

Palavras-chave: medo; personagem; Rui Zink; A instalação do medo

\section{THE CHARACTER AND THE FEAR REPRESENTATION AS MAINSTAYS OF PLOT IN $A$ INSTALAÇÃO DO MEDO, BY RUI ZINK}

Abstract: Based on the theoretical reflections by Michel Zéraffa (2010) and Carlos Reis (2014), in the fields of Theory of Novel and Narratology, this article aims at analyzing the building process of A instalação do medo (2012), by the Portuguese novelist Rui Zink. This analysis start from the principle that the novel utilizes flat characters, as understood by E. M. Forster, to build not only the reality in which they are inserted, but also to establish a possible reading of the reality in which the reader belongs, characterizing the metalepsis, as comprehended by the narrative studies theory.

Keywords: fear; character; Rui Zink; A instalação do medo

Roland Barthes, em O gran z̧ero da escrita, ao problematizar, triangularmente, a relação entre realidade, literatura e linguagem, traz à discussão a marca (desaparecida da fala) do passésimple, como "signo operacional pelo qual o narrador reduz a explosão da realidade a um verbo tênue e puro, sem densidade, sem volume, sem desdobramento" (BARTHES, 2004:28). Ainda sobre esse aspecto da linguagem narrativa, o autor diz que

(...) quando no interior da narração o "passe simple" é substituído por formas menos ornamentais, mais frescas, mais densas e mais próximas da fala (o presente ou o "passe composé"), a Literatura se torna depositária da espessura da existência, e não de sua significação. Separados da História, os atos não ficam mais separados das pessoas. (BARTHES, 2004:29)

Nesse sentido, a leitura de $A$ instalação do medo (2012), do escritor português Rui Zink, estabelece nítido exemplo do pensamento de Barthes, no que diz respeito ao estabelecimento de uma "espessura da existência" na escrita literária. O romance é estruturado em quatro partes, as quais, por sua vez, se constituem predominantemente de cenas, como as concebe

${ }^{1}$ Professor Adjunto da área de Literatura Portuguesa do Departamento de Letras da Universidade Federal do Rio Grande do Norte. Doutor em Letras (Literatura Portuguesa) pela Universidade de São Paulo (2013). 


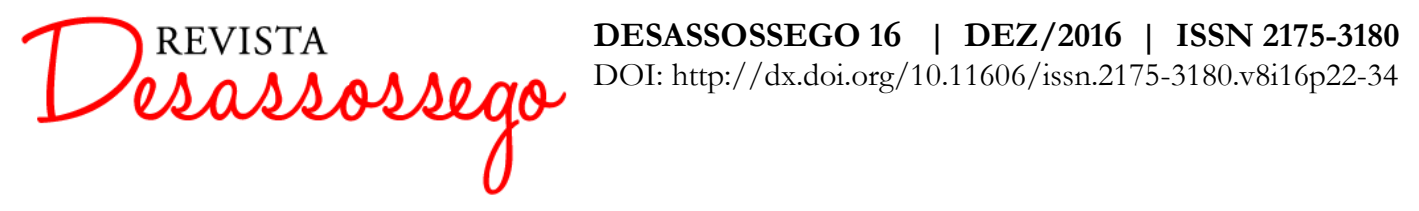

Percy Lubbock, entremeadas por referências a outras obras literárias e inserções de recortes de outros gêneros textuais, como crônicas jornalísticas e e-mails recebidos pelo próprio autor, por exemplo.

O enredo de $A$ instalação do medo é, a princípio, simples: dois funcionários do governo português comparecem a uma residência para instalar, a mando da Administração Pública, um novo equipamento de uso obrigatório:

- A senhora sabe que a instalação do medo é um objetivo patriótico. Directiva no 359/13. Portaria 8: "Todos os lares devem ter o medo instalado num prazo de 120 dias." Conhece a portaria, não conhece?

- Bem...

- E a directiva?

- Sim...

- É importante. Uma efeméride. Crucial para o bom funcionamento. É crucial para o bem de todos que a instalação do medo seja feita de forma atempada e ordeira e que os prazos de integração sejam cumpridos. (ZINK, 2012:13)

A partir dessa situação inicial, Carlos (o "bem-falante") e Sousa (o instalador) procedem à instalação e demonstram à mulher, dona da casa, todas as possibilidades de funcionamento do medo, em uma sucessão de cenas que remetem à propaganda de um equipamento eletrônico, como um receptor de TV a cabo. Entre os medos, aparecem desde os mais comuns, como os de animais venenosos, até os mais complexos, como o das oscilações do mercado em um mundo capitalista, ou o do terrorismo. Depois de uma exaustiva demonstração (durante a qual, diga-se, apontam discussões de caráter sociopolítico e econômico), os funcionários da instalação do medo acabam mortos por uma mulher cuja mentalidade, agora se revela, oscila entre a lucidez e a loucura.

Uma análise mais atenta das passagens cênicas aponta para a formulação de Roland Barthes, no tocante à relação entre a realidade externa à narrativa e sua materialidade textual. Predomina, no texto de Zink, o discurso direto, em uma modalidade linguística simples, oralizada, ao longo do qual as interpelações de um narrador intruso, na maior parte das vezes, fazem o papel das rubricas de um guião, direcionando o leitor no que diz respeito a detalhes que as falas das personagens, em um texto escrito tal como cena teatral, não dariam conta de deslindar, como se vê no exemplo a seguir:

A mulher assente. $\mathrm{O}$ que mais pode fazer? $\mathrm{O}$ que mais pode fazer se não assentir?

$\mathrm{O}$ bem-falante sussurra, contra-regra soprando a deixa à desmemoriada diva:

- Diga que sim, minha senhora. 


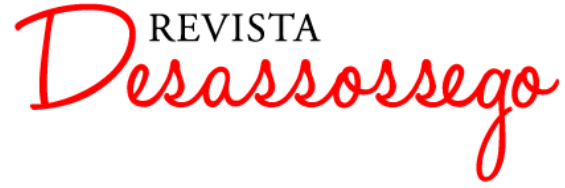

DESASSOSSEGO 16 | DEZ/2016 | ISSN 2175-3180

DOI: http://dx.doi.org/10.11606/issn.2175-3180.v8i16p22-34

\author{
- S-sim... \\ O rosto do bem-falante descontrai, como que de alívio. \\ - Muito bem, minha senhora. Significa isso então que podemos \\ entrar. (ZINK, 2012:14-15)
}

Tudo isso a serviço da construção de uma realidade a partir da interação entre as três personagens, em torno das quais toda a trama se constituirá, procedimento que, nas palavras de Barthes, traz à obra a "espessura" da realidade, em detrimento de sua mera "significação". Importante notar que, além da própria realidade construída a partir da interação, apontamse de imediato os primeiros procedimentos discursivos que problematizam a questão do medo, o sentimento regente da narrativa de Zink e que aparece, como de se esperar, desde o título da obra: o silenciamento da mulher e a imposição, por meio de um sórdido jogo de pretensa simpatia, da linha de pensamento "correta".

Ainda a respeito da construção da narrativa de ficção e sua relação com a realidade, Michel Zéraffa, em Pessoa e personagem (2010), afirma, ao problematizar as transformações experimentadas pelo romance ao longo das primeiras duas décadas do século XX:

Em nossos dias, pode parecer evidente que o valor estético de uma obra romanesca se reconhece e se mede pelas mediações que o escritor descobre, instaura, entre si mesmo e um certo estado do real, tal como ele o observou, e que destas mediações - destas formas, destas técnicas - depende precisamente o realismo do romance (...). Por mais poderosas e singulares, por mais ambíguas e complexas que sejam as personalidades de Vautrin, JulienSorel ou Jane Eyre, por exemplo, estas personalidades não são separáveis da sociedade nem da história. (...) $\mathrm{O}$ autor de Portraitof a Lady (Retrato de uma Senhora) vai substituir esta relação [indivíduo-sociedade] por aquela de consciência-meio, dando então a primazia à vida subjetiva, espaço em constante expansão, por oposição a este sistema que é o social. (ZÉRAFFA, 2010:19)

Nesse sentido, a reflexão de Zéraffa aponta para um fenômeno crucial, no tocante à construção da trama de um romance, especialmente no que diz respeito à função das personagens de uma obra na construção da relação entre ficção e realidade: elas deixam de ser recortes dos valores e das práticas da sociedade em que se inserem, passando a construir, ao longo da própria narrativa, uma realidade a partir de seu posicionamento subjetivo diante dos fatos que vivem; não é mais possível, portanto, compreender a personagem de ficção como um produto da sociedade extra-romance: mais do que um tipo representativo, ela é o referencial para o contexto sociopolítico e econômico em que se desenrola a trama. Em outras palavras: não se lê mais a sociedade em uma personagem; lê-se a personagem inserida em uma realidade, a qual ela mesma - a personagem - constrói a partir de seu lugar de fala. 


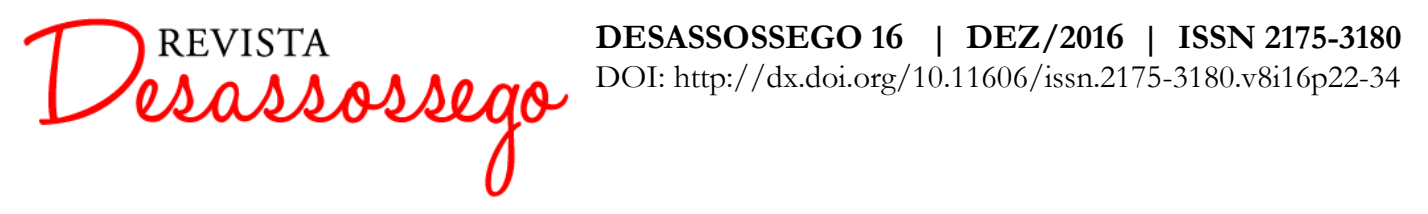

Essa constatação aponta, portanto, para o fato de que, na trama romanesca, a partir da década de 1920 (seria esse o ponto inicial, segundo Zéraffa, do surgimento das obras que estabelecem novos paradigmas para a construção romanesca), reside na constituição das personagens o ponto fulcral para o desenvolvimento de um romance, uma vez que é a partir da subjetividade de sua experiência que se construirão contexto e cenário, com reflexos nas relações que se estabelecem entre ficção e realidade.

No caso do romance de Rui Zink, a observação de Zéraffa toma corpo, na medida em que, desde os primeiros momentos, é na interação entre as três personagens da obra que se constroem a noção de realidade e a sensação de medo depreendidas pelo leitor: a partir do estabelecimento pontual de informações (as já mencionadas "Directiva no 359/13. Portaria 8”)que remetem à realidade política de uma sociedade - ainda não se pode dizer, com clareza, que se trate de Portugal, embora, ao longo do romance, outros dados apontem para isso -, constrói-se uma trama em que é da vivência das personagens nessa interação que emerge o funcionamento da sociedade global e, nela, a presença - e a função - do medo:

À mulher quase parece que os dois se metamorfoseiam em artistas de variedades. Chapéu palha, casaco às riscas azuis e brancas, a indispensável bengala para rodarem em sincronia.

Não, não cantam. Não cantam, mas também não se calam. falante Carlos.

- A senhora decerto já ouviu falar dos mercados - diz o bem-

- Pois fique sabendo que, ao contrário das pessoas, os mercados são sensíveis, emocionais - diz o Sousa.

- Nervosos, muito nervosos - diz Carlos.

- Neurasténicos mesmo - diz o Sousa.

- Os mercados reagem muito rapidamente - diz Carlos.

- Os mercados apostam - diz o Sousa.

- Os mercados investem - diz Carlos.

- Os mercados acreditam - diz o Sousa.

- Os mercados desconfiam - diz Carlos.

- Os mercados receiam... - diz o Sousa.

- E quando receiam... - diz Carlos.

- Os mercados ficam instáveis - diz o Sousa. (ZINK, 2012:52)

O trecho acima aponta para duas das principais características do discurso instaurado em $A$ instalação do medo: a estrutura cênica, que privilegia a interação entre as personagens, em detrimento das intervenções digressivas de um narrador que estabeleça as relações com a realidade, e, dentro dessa estrutura cênica, a rápida troca de turnos conversacionais, a qual imprime uma velocidade narrativa elevada. Tais elementos, além de aproximarem o texto de Zink da estrutura do texto dramático, viabilizam o protagonismo das personagens, no que diz respeito à problematização de questões sociopolíticas e econômicas. 


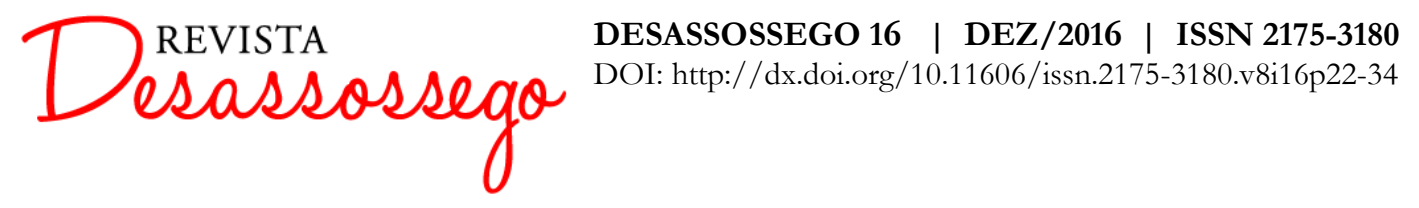

A rigor, pode-se ler, em $A$ instalação do medo, algumas manifestações discursivas as quais visam, do ponto de vista da relação entre enunciador e leitor, ao estabelecimento da atmosfera de medo, na qual se inserem as três personagens do romance, bem como o delineamento dos perfis de amedrontadores (ou "operadores do medo") e amedrontada (a "cliente" da dita instalação: a) a reiteração de frases curtas, rapidamente enunciadas, como se fossem pronunciadas em avalanche, a fim de que a personagem que as ouça não tenha espaço para reagir; b) o fato de que, ao longo da trama, tanto tempo quanto espaço adquirem características difusas - não se sabe onde, nem por quanto tempo, a mulher fica presa em uma sala com dois homens que lhe expõem a toda espécie de situação amedrontadora, em uma situação que remete à imagem de uma sala de torturas, típica dos períodos ditatoriais; e c)o turno de fala de Carlos e Sousa são significativamente mais longos do que os da mulher, em uma espécie de silenciamento daquela que deverá ser submetida ao medo a ser instalado.

Tais procedimentos constituiriam, por assim dizer, o discurso do medo que torna o romance de Rui Zink uma trama coesa e coerente, a partir de cuja leitura pode-se discutir não apenas o texto do romance, mas a maneira como ele se articula com os planos (político, econômico e ideológico) da sociedade de consumo da qual fazem parte leitor e personagens.

A leitura do trecho aponta, ainda, para o fato de que a discussão estabelecida acerca do funcionamento do mercado financeiro reflete um posicionamento diante do pensamento capitalista, o que, a rigor, implica dizer que há, em $A$ instalação do medo, a presença da realidade social na construção da trama, não apenas como pano de fundo, mas como elemento problematizado pelos diálogos entre as personagens.

Note-se, também, que a referência à dinâmica econômica da sociedade é dada pela reiteração da expressão "os mercados", expressão que cunha a entidade abstrata, o "mercado", que, tal como as alegorias das narrativas da tradição, têm vida própria e rege as existências das pessoas "comuns". Essa ideia difusa de "mercados" contribui para construir, em $A$ instalação do medo, uma sociedade que se compreende apenas pelo que sentem e vivenciam as personagens: é a sociedade do medo: medo dos animais peçonhentos, do mercado, dos imigrantes; medo.

Em outro trecho da obra, as personagens Carlos e Sousa, dirigindo-se à dona da casa em que se instala o "produto", dão a entender como deve funcionar, subjetivamente, a percepção do medo:

O bem falante Carlos volta-se para a mulher, todo ele riso:

- A senhora não percebe patavina, pois não? 
A mulher nada diz. O que há para dizer?

- Não se preocupe, é essa mesma a ideia - O sorriso de Carlos é fino, à entendido. - Faz parte do plano.

- Integra-se à beleza do conceito - acrescenta o Sousa, não sendo claro se para corrigir ou explicitar melhor as palavras do colega.

- Sim, a beleza do conceito é sempre o mais importante - admite Carlos. Compreenda, minha senhora, a instalação do medo é um processo de cooperação. Um processo. Mesmo quando desligado, o medo deve estar ligado.

- Deve estar lá - complementa o Sousa. - Sempre lá.

- Ou seja, aqui - diz Carlos, apontando para a cabeça.

- Aqui - diz o Sousa encostando a mão ao peito.

- E também aqui, claro - Carlos, rindo, põe a mão sobre a braguilha.

- Aqui - diz o Sousa, dando uma palmada (ligeira) no traseiro da mulher que, impreparada, estremece.

Não estremece muito, contudo. A mulher, honra lhe seja feita, não estremece muito quando o Sousa lhe dá a palmada (ligeira) no traseiro. (ZINK, 2012:77)

Em que pese a ironia da escrita de Rui Zink, o trecho evidencia o conceito proposto por Zéraffa: a construção do que, a princípio, levaria a mulher a compreender e sentir o medo vem de seu contato com a experiência que lhe propõem os instaladores; não há uma construção apriorística dos medos que afligem a dona da casa; ao contrário, eles são constituídos e compreendidos por meio do contato com as imagens que lhe vão sendo mostradas. O mesmo se dá na esfera da recepção: as questões sociopolíticas e econômicas que constituem as experiências de medo não são discutidas, ou propostas, pelo narrador; vão-se construindo as referências sociais à medida que a interação entre as personagens vai desenrolando-se.

Faz-se necessária, a esta altura, uma observação a respeito da categoria de personagens que Rui Zink constrói em $A$ instalação do medo, à luz das considerações de Michel Zéraffa: ao contrapor as personagens de Retrato de uma Senhora às de O Pai Goriot, O Vermelho e o Negro e Jane Eyre, Zéraffa deixa implícita a ideia de que, na nova configuração do romance, a já apontada relação entre consciência e meio será construída pela subjetividade de uma personagem mais complexa, ou esférica, de acordo com a mais-que-consagrada nomenclatura proposta por E. M. Forster (2005).

No caso do romance de Rui Zink, a escolha recai, nitidamente, sobre as personagens planas, cujas personalidades se definem de imediato, pela exacerbação de um traço comportamental explícito: Carlos (o "bem-falante”) e Sousa (o “instalador), responsáveis por instalar e demonstrar o medo, apresentam-se, desde o primeiro momento, como homens que executam, burocraticamente, o serviço que lhes é designado pelo governo. No caso de 


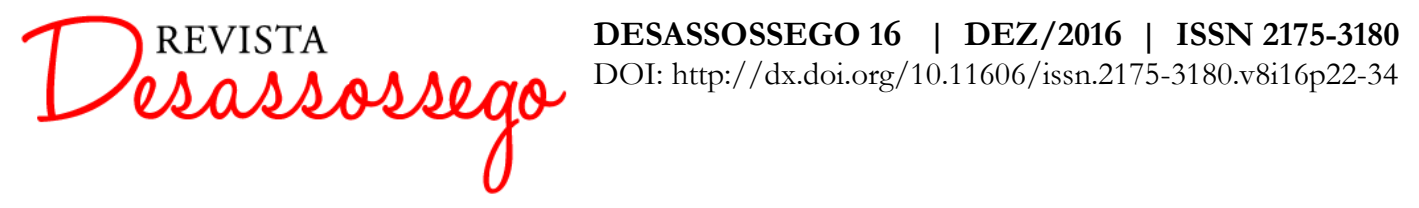

Carlos, particularmente, a insígnia de "bem-falante" reforça ainda mais sua condição de personagem plana: a ele, cabe a tarefa de, verborragicamente, ressaltar todas as qualidades do aparelho que impõe à dona de casa. Por outro lado, Sousa, o instalador, ainda que aja de modo surpreendente em algumas das passagens do romance, não chega a surpreender o leitor; suas atitudes são, na maioria, condizentes com o perfil que se constrói desde a primeira cena da obra. Trata-se, portanto, de duas personagens tipificadas, cujas atitudes e palavras constroem, no decorrer de $A$ instalaşão do medo, a realidade em que a trama se dá.

Tal escolha representaria, assim, em um primeiro momento, uma contradição com a teoria de Zéraffa; entretanto, o próprio teórico pondera, um pouco mais adiante, que “(...) o romancista não reproduz o objeto que privilegia, mas estrutura-o e o interpreta de maneira a mostrar sua essência e significação: esta correspondência necessária entre o formal e o real varia, porém, segundo as épocas.” (ZÉRAFFA, 2010:25).

Aí reside a explicação para a escolha de Rui Zink: a "essência" e a "significação" das personagens de $A$ instalação do medo constituem a superficialidade de uma sociedade na qual, como se vê no texto do romance, o medo, mais do que naturalizado, é institucionalizado e, até mesmo, parte de um projeto "crucial para o bem-estar de todos", uma "efeméride". Carlos e Sousa, portanto, aos olhos do leitor, constroem, por meio de sua existência, uma configuração social que, em última instância, é a face "ficcional" de uma sociedade "real": é tão plana quanto a vivência subjetiva de suas personagens tipos, não aparecendo no texto como "espaço", "cenário", "ambiente”, ou nenhuma outra categoria narrativa que diga respeito ao lugar da ação cênica.

$\mathrm{Na}$ esteira desse pensamento, vale trazer à baila a noção de figuração, extraída dos domínios da narratologia (ou "estudos narrativos"), conforme a compreende Carlos Reis: “entende-se por figuração o processo discursivo e metaficcional que, em diferentes momentos da composição de um relato, conduz à individualização de uma personagem num universo ficcional." (REIS, 2014).

Uma análise do "processo discursivo" empregado para a construção das personagens aponta para a constatação de que, a rigor, sua "individualização" ocorre à medida que a trama se desenrola; em outras palavras: as personagens constroem-se (tornam-se indivíduos) diante do leitor quando falam e agem, em processo simultâneo com o próprio desenvolvimento da narração, o que aponta, inequivocamente, para o fato de que, em $A$ instalação do medo, é a construção das personagens planas que constitui o esteio narrativo da obra. Construí-las é, 
portanto, construir o próprio enredo e apontar, na esfera extratextual, para os medos que vêm assombrando a sociedade portuguesa e, por sinédoque, a europeia.

Tome-se, a título de exemplo desse "processo discursivo" de que fala Reis (2014), a cena a seguir:

- Pois é, minha senhora.

- Factos são factos, minha senhora.

- O medo vem aí. Queiramos ou não.

- Ao princípio, estranha-se, depois entranha-se.

- É o que dizem as pessoas.

- O medo vem aí.

- Evai ser bom.

- Rápido.

- Indolor.

- Enfim, quase.

- A verdade é que alguém tem de sofrer.

- Alguém tem de sofrer para os outros poderem viver.

- Dividir tudo por igual ficava tudo igualmente pobre, minha senhora.

(...)

- A verdade é que são precisos sacrifícios, minha senhora.

- Sacrifícios humanos.

- Os únicos que ainda talvez funcionem.

- Imolar cordeiros em vez de pessoas? Veja no que deu.

- As Forças do Mundo não gostam de ser enganadas, minha senhora.

(...)

- E alguém tem de ser sacrificado.

- Uma minoria.

- Uma minoria de cada vez.

- Com sorte não nos calha a nós.

- Em boa verdade, a possibilidade de nos calhar a nós é menor do que a de não calhar.

- Então, se as estatísticas estão a nosso favor... para quê levantar ondas?

- Se levantarmos ondas é ainda pior, minha senhora.

- Quem avisa amigo é.

- É também para isto que serve a instalação do medo.

- Para tornar as pessoas mais avisadas.

- Não cometerem estupidezes.

- Cometer estupidezes é estúpido, minha senhora. (ZINK, 2012:124-125, sublinhados nossos)

Ao longo da narrativa, Carlos e Sousa, repetidas vezes, travam diálogos nos quais instituem, na cena, uma discussão sobre as diferentes feições do medo. Tais diálogos mantêm, quase sempre, um conjunto de características discursivas que, ao mesmo tempo em que reforçam, para o leitor, a ideia da construção de um cenário de medo, dão a conhecer as próprias personagens, bem como sugerem os mecanismos pelos quais, em uma sociedade 


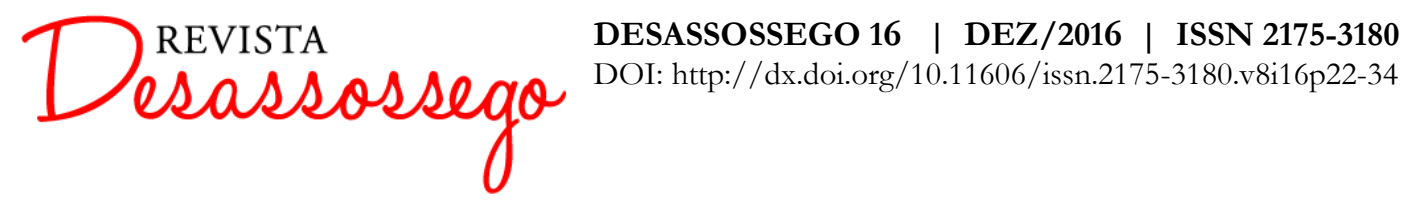

real, os medos são propagados e sedimentados, a serviço, quase sempre, da manutenção de uma relação de dominação socioeconômica.

Nesse sentido, as passagens sublinhadas apontam para algumas características importantes, não apenas dos medos apresentados por Carlos e Sousa, mas do "público" a quem se destina o "produto", o medo instalado por decisão governamental. Uma leitura atenta do trecho dado denota com clareza a relação que se estabelece entre o funcionamento da sociedade capitalista (provavelmente, a sociedade da Zona Euro, que desde 2010 vive uma crise econômica séria, em que os casos de Grécia, Portugal, Itália e Espanha foram os mais notáveis) e os sacrifícios necessários para esse funcionamento.

Por um lado, expressões como "o medo vem aî", "alguém tem de sofrer", "são precisos sacrifícios", "alguém tem de ser sacrificado", "uma minoria", entre outras, denunciam o cruel funcionamento de um sistema baseado na concentração de renda e poder em detrimento de alguma justiça social; afinal de contas, são as "minorias" (as quais, ironicamente, constituem a maioria numérica da população mundial) a pagarem pela manutenção do status quo que garantem a estabilidade ilusória da sociedade - e a simples perspectiva de uma mudança, de se levantarem "ondas" aflige uma parcela relevante das pessoas. É o discurso do medo a garantir uma dinâmica de privilégios garantidos pelo poder econômico.

Por outro lado, fica patente que o medo de uma reviravolta se adequa a um grupo específico da população, o que não se julga - ou não se quer reconhecer - parte das "minorias" que devem se submeter a sacrifícios. Insinua-se, assim, no discurso de $A$ instalação do medo, que as amarras impostas pelo temor à dinâmica dos mercados econômicos atingem diretamente a parcela do mundo afinada com o que se define como "classe média", temerosa de aproximar-se das "minorias" e ansiosa por manter-se próxima (ainda que de maneira ilusória) das classes superiores. Tal leitura surge da própria natureza do funcionamento do capitalismo - parece lógico que, para alguém acumular capital, outro alguém será dele privado - e da ideia de que o alijado do funcionamento ideal do sistema será o outro, um "alguém" que, com sorte, "não nos calha a nós".

Em que pese a discussão acerca da relação entre realidade e construção ficcional na constituição da personagem, a qual se discutirá mais adiante, é relevante notar, no trecho dado, alguns dos traços discursivos que caracterizam Carlos e Sousa como tipos humanos, 


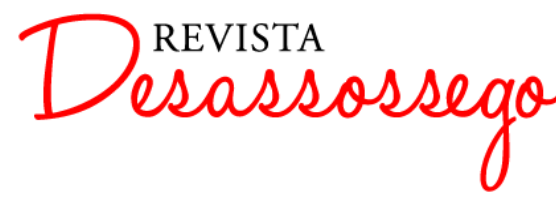

DESASSOSSEGO 16 | DEZ/2016 | ISSN 2175-3180

DOI: http://dx.doi.org/10.11606/issn.2175-3180.v8i16p22-34

ou, em outros termos, figuras, que, ficcionalizadas, tornam-se, no romance de Zink, personagens planas.

Chama atenção, à partida, a reiteração da expressão "minha senhora", comumente tomada como signo de distanciamento respeitoso, mas que, ao mesmo tempo, institui, por meio da ironia típica da paródia, uma espécie de relação hierárquica inversa: se, por um lado, Carlos e Sousa chamam "minha senhora" à suposta cliente (com quem teriam, por assim dizer, uma relação de subalternidade, de "servidor" a "cliente"), por outro, o uso dessa expressão deixa transparecer certa ideia de superioridade por parte de quem a diz, chamando a cliente de "minha senhora" por uma espécie de obrigação desdenhosa, uma gentileza mandatória por parte de quem, na cena, está ali para dominar a situação.

Outra forma de reiteração que reforça essa percepção é a de algumas ideias-chave ao longo do diálogo, tanto por meio de repetições sintático-semânticas, quanto por meio da retomada de ideias: as noções de "medo", "necessidade de sacrifícios", "minorias" aparecem, ao menos, duas vezes ao longo da passagem, sempre de forma alternada - em que Carlos reforça o que disse Sousa, e vice-versa.

Tal construção discursiva imprime à construção das personagens algumas características marcadas: o uso de frases curtas e reiterativas sugere, fortemente, que se trata de um discurso raso, o qual obedece a um script, repetido à exaustão, e cujos efeitos de sentido são previamente conhecidos; neste caso, estabelecer um cenário aterrorizante, que desperte, na dona de casa, a sensação de medo. Esse traço pode, portanto, ser lido como índice do comportamento "burocrático" das personagens, as quais, desde o primeiro momento, apresentam-se como funcionários a serviço de uma entidade - o governo português.

Em decorrência disso, sugere-se, ainda, que os dois homens não tenham autonomia de pensamento: cumprem uma missão instituída pela entidade que os emprega - e, nesse sentido, torna-se quase inevitável relacioná-los a uma figura da realidade, o vendedor de aparelhos, cujo discurso se constitui de frases feitas, clichês corporativos e exortações à compra - ou à aceitação - do "produto", muitas vezes, por meio da mera repetição dessas frases.

A esse respeito, pondera Reis, sobre a relação entre as figuras da ficção e a realidade que "as figuras reais, cuja existência é empiricamente verificável, podem ser objeto de figuração ficcional, por proposta própria ou por iniciativa de outrem.” (REIS, 2014). 


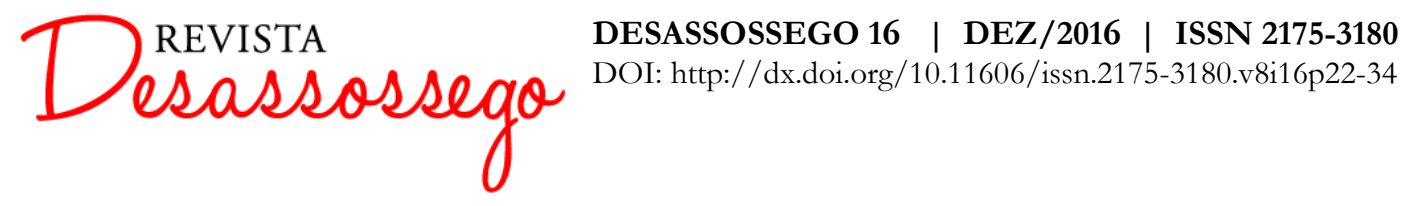

Logo, é possível afirmar que, ao criar suas personagens, Rui Zink constrói, em $A$ instalação do medo, figuras que se relacionam com a existência "empiricamente verificável", no intuito de, por meio de sua trajetória na trama, trazer à tona questões de fundo relacionadas à sociedade portuguesa; entretanto, é preciso notar que, a despeito dessa relação, não é a sociedade quem fornece as figuras; são as personagens do romance de Zink que constroem a visão acerca da sociedade em que se inserem e, ao mesmo tempo, se relacionam com a realidade portuguesa.

Outro aspecto do discurso das personagens que chama atenção - e que reforça o estabelecimento da ponte entre a ficção e a existência "empiricamente verificável" - é a presença, não só na cena em questão, mas ao longo de toda a obra, de relações intertextuais, seja por meio de citações diretas ou indiretas, por meio da inserção de recortes de outras formas de discurso, ou pela incorporação, nas falas das personagens, de frases ou de ideias conhecidamente de autoria externa ao texto do romance. É o caso, por exemplo, da frase: "Primeiro, estranha-se; depois, entranha-se", elaborada por Fernando Pessoa, por volta de 1927, para servir de slogan à Coca-Cola, que planejava sua entrada em Portugal.

Ao aparecer em uma cena que evoca o medo gerado pela instabilidade do mercado e suas consequências, a frase recobra parte de seu trajeto histórico: por conta da associação da frase à aquisição de um vício - o "entranhar-se” da frase pessoana -, o órgão responsável pela circulação de alimentos, à época, proibiu a venda do produto em território português. Tal proibição pode ser vinculada ao medo que as autoridades sanitárias tiveram de que a população consumisse algo considerado tóxico. Consequentemente, a presença da frase no texto de Zink reforça não apenas a ponte entre a realidade e a ficção, mas o faz mantendo a citação vinculada à ideia de medo e, também, à sensação de algo que seja apenas "questão de hábito"; é preciso acostumar-se com o medo, a "efeméride" instalada para "o bem de todos".

Ainda sobre a ocorrência da figuração ficcional, Carlos Reis afirma que ela "situa-se num plano ontológico que liberta as figuras ficcionais do conceito de mentira e das valorações ético-morais que tal conceito implica" (REIS, 2014).Essa característica das figuras ficcionais permite que, no romance, a própria situação inicial - a instalação do medo de que trata o título - seja possível, bem como os argumentos utilizados por Carlos e Sousa sejam compreendidos como tal no contexto da trama; ao ingressar na narrativa, o leitor encontrase em uma esfera de realidade que não guarda relações com os "valores ético-morais" de que 


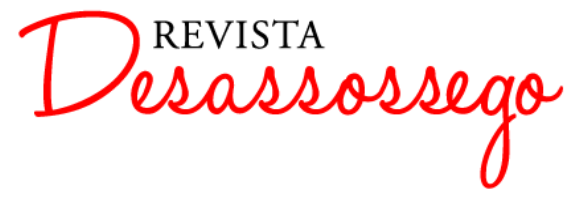

DESASSOSSEGO 16 | DEZ/2016 | ISSN 2175-3180

DOI: http://dx.doi.org/10.11606/issn.2175-3180.v8i16p22-34

fala Reis. Logo, torna-se possível, por exemplo, que o medo seja um aparelho a ser instalado e demonstrado, como ocorre ao longo de todo o romance.

Entretanto, conforme apontado anteriormente, há em $A$ instalação do medo diversas situações em que a relação com a "experiência empírica" torna-se patente: a partir da realidade construída pelas personagens, o leitor pode construir uma leitura de sua própria realidade, especialmente porque aparece ao longo da trama todo um arcabouço de ideias, conceitos e posicionamentos político-sociais, o que acaba por ser uma das possíveis características do processo de figuração (cf. REIS, 2014).

A descrição da dinâmica de mercado, a própria noção de "instalação do medo" como algo institucionalizado, praticado pelo governo, a consequente naturalização da sensação de insegurança e medo constituem a verdade real das personagens, ao mesmo tempo em que ecoam procedimentos e posicionamentos também perceptíveis na esfera da realidade do leitor. É a metalepse, como a compreende a narratologia: a construção do sentido das cenas e imagens do texto partem da materialidade do texto, da realidade figurada pelo discurso das personagens, mas a transcende, chegando ao universo da realidade do leitor e permitindolhe realizar uma leitura crítica de sua própria condição.

Um dos instrumentos, na construção do discurso das personagens, que apontam para a possibilidade da metalepse no romance é o uso de frases feitas, repetidas à exaustão, e que apontam, em alguma medida, para o fato de que alguns dos piores medos de uma sociedade (a xenofobia e o medo da instabilidade do mercado, por exemplo) derivam do desconhecimento - ou da inexistência - de um sujeito conhecido; em seu lugar, uma imagem do "estrangeiro" ou do "mercado", normalmente aterradora e abstrata - e, por isso mesmo, passível de generalizações:

O bem-falante Carlos apaga a visão. Incomodada com a súbita mudança de luz, a mulher esfrega os olhos. O bem-falante mostra as palmas das mãos. Nada nesta palma, nada naquela palma...

- Uma maravilha, não é? Um dos mais belos e perfeitos medos que há. Porque é um medo que se alimenta a si próprio. Pela sua simples evocação, o medo da crise económica tem por efeito secundário (eu diria até primário) criar uma crise econômica.

O Sousa interfere:

- Mas a verdade é que...

Carlos, o bem-falante, sorri;

- A situação econômica é deveras preocupante.

É estranho, mas agora o Sousa parece falar em itálico:

- Provavelmente vamos ter de sair da moeda única.

- O que vai acarretar consequências sérias.

- Andámos a gastar maios do que devíamos. 
- Agora pagamos o preço.

- Construímos estradas de que não precisávamos.

- Nós?, perguntará a senhora.

- Nós, respondemos nós.

- Os mercados perderam a confiança.

- E têm razão.

- Têm razão.

- Os mercados têm sempre razão.

- Os mercados são irracionais.

- Mas têm sempre razão.

- É uma alegria.

- É o que é.

- Há que tomar medidas corajosas.

- Impopulares.

- As pessoas não compreendem.

- Não, não compreendem.

- Não compreendem.

- Os sacrifícios que fazemos por elas. (ZINK, 2012: 94-95, sublinhados nossos)

Dessa forma, é possível concluir que, em $A$ instalação do medo, são as figuras construídas por Rui Zink as responsáveis por estabelecer, subjetivamente, a realidade em que se conduzirá a narrativa, a partir da qual o leitor pode, entre outras possibilidades de leitura, enxergar relações com sua "experiência empírica", no contexto da sociedade em que ele se encontra e se constrói como sujeito. Em outras palavras, as questões de fundo do romance aparecem não como representação da sociedade do leitor, mas como vivência das personagens planas, as quais são, por isso, o esteio da trama. Nela, a relação entre indivíduo e sociedade aparece problematizada a partir das consciências das personagens, e não o contrário.

\section{REFERÊNCIAS}

BARTHES, Roland. O gran zero da escrita. São Paulo: Martins Fontes, 2004. FORSTER, E. M. Aspectos do romance. 4a . Edição. São Paulo: Globo, 2005.

REIS, Carlos. "Figuração política e vida real". In Figuras da Fição. Disponível em https://figurasdaficcao.wordpress.com/2014/08/07/figuracao-politica-e-vida-real/. Acesso em 15.ago.2016 ZÉRAFFA, Michel. Pessoa e personagem: o romanesco dos anos de 1920 aos anos de 1950. São Paulo: Perspectiva, 2010. Pp. 19-21)

ZINK, Rui. A instalação do medo. Lisboa: Teodolito, 2012. 